\title{
Modular diphosphine ligands based on bisphenol A backbones
}

\author{
Jarl Ivar van der Vlugt, ${ }^{\mathrm{a}}$ Josep M. Bonet, ${ }^{\mathrm{a}}$ Allison M. Mills, ${ }^{\mathrm{b}}$ Anthony L. Spek ${ }^{\mathrm{b}}$ and Dieter Vogt ${ }^{\mathrm{a}, *}$ \\ ${ }^{a}$ Schuit Institute of Catalysis, Laboratory of Homogeneous Catalysis, Eindhoven University of Technology, PO Box 513, \\ 5600 MB Eindhoven, The Netherlands \\ ${ }^{\mathrm{b}}$ Department of Crystal and Structural Chemistry, Padualaan 8, University of Utrecht, The Netherlands
}

Received 19 November 2002; revised 3 April 2003; accepted 10 April 2003

\begin{abstract}
A straightforward two-step synthesis is used to obtain new phosphorus-containing ligands based on readily available bisphenol A type backbones. Five diphosphine ligands have been prepared in good yields. An X-ray crystallographic study is presented for ligand 5. Preliminary results on rhodium-catalyzed hydroformylation exemplify the use of these ligands for homogeneous catalysis. (C) 2003 Elsevier Science Ltd. All rights reserved.
\end{abstract}

Homogeneous catalysis has proven to be a very powerful tool for the synthesis of various intermediates and fine chemicals. ${ }^{1}$ The success of homogeneous transition metal catalysts strongly depends on the ligands used. A large number of the ligands applied in such reactions are based on phosphorus donors and backbones such as biphenyl, ${ }^{2}$ xanthene ${ }^{3}$ or norbornene. ${ }^{4}$ Frequently the starting materials are either expensive or not commercially available. In addition, structural variations and exchange of functional groups is not always easy in these systems while nowadays the aim is to create modular, highly variable ligand classes made from readily available materials.

We have selected bisphenol $\mathrm{A}$ and its derivatives as starting compounds for the development of modular ligand classes. A broad variety of these bisphenols are commercially available at low cost since they are major components in epoxy resins. ${ }^{5}$ Generic structures are easily accessible by simple acid-catalyzed condensation of a ketone with two molecules of a phenol. Here we report the first examples of a new class of ligands based on bisphenol A type backbones. Their application in the rhodium-catalyzed hydroformylation of 1-octene exemplifies their use and potential for homogeneously catalyzed reactions.

Based on three derivatives of bisphenol A, we applied a simple, straightforward two-step synthetic route (Scheme 1). The approach was to use protected phenolic $\mathrm{OH}$-groups as directing groups for the selective ortho-lithiation of both phenyl rings followed by reac-<smiles>[X]c1ccc(O)cc1</smiles>

Scheme 1. Synthetic methodology to generic ligands 1-4. Reagents and conditions: (i) $\mathrm{MeI}, \mathrm{K}_{2} \mathrm{CO}_{3}$, acetone, reflux $16 \mathrm{~h}, 85 \%$; (ii) $n$-BuLi, TMEDA, $-15^{\circ} \mathrm{C}$, ether, $1 \mathrm{~h}$, then $\mathrm{SiCl}_{2} \mathrm{Me}_{2}, 72 \%$; (iii) $n$-BuLi, TMEDA, $-15^{\circ} \mathrm{C}$, ether, $16 \mathrm{~h}$, then $\mathrm{ClPPh}_{2}, \mathrm{hexanes}^{\circ} \mathrm{C}$, $16 \mathrm{~h}, 60 \%$.

Keywords: bisphenol A; terphenyl; modular backbone; diphosphine ligand; homogeneous catalysis; rhodium.

* Corresponding author. Tel.: +31 40 2472483; fax: +31 40 2455054; e-mail: d.vogt@tue.nl 
tion with a suitable phosphorus compound, in this case $\mathrm{ClPPh}_{2}$. In this manner a wide range of phosphorus containing ligands is accessible. Using this method we obtained ligands 1-3 based on bisphenol A derived backbones. $^{6}$

This modular approach allows for variation in rigidity, steric bulk and electronic properties of the ligands. Introduction of other P-containing groups is also on option, leading to, for instance, phosphonites. ${ }^{7}$ Taking advantage of the selective ortho-lithiation approach, and starting from 4-bromoanisole we also synthesized a silicon-bridged bisphenol ligand $\mathbf{4}$ as well as a ligand based on a terphenyl backbone, ligand 5, which we have named Terphos (Scheme 2). In this latter case, the appropriate backbone, compound II, which was obtained in two steps via palladium-catalyzed Suzukicoupling using 1,2-dibromobenzene, has been reported by Blake et al., with a yield of only $66 \%$ when using $\mathrm{Ba}(\mathrm{OH})_{2}$ as the base. ${ }^{8}$ We improved the yield of this particular reaction to $85 \%$ using $\mathrm{Na}_{2} \mathrm{CO}_{3}$ as the base. Simple workup by filtration and evaporation of the solvent followed by washing of the crude product with methanol afforded the pure compounds in overall yields of $40-50 \%$.

Ligand 5 could be crystallized from hot acetonitrile which gave crystals suitable for X-ray analysis. 9 The molecular structure of $\mathbf{5}$ is depicted in Figure 1 together with selected bond lengths and angles. The terphenyl backbone has an approximately $C_{2}$ symmetry, the two peripheral aromatic rings being tilted at angles of 48.22(9) and $49.70(9)^{\circ}$ with respect to the central ring. Because of the rotational freedom of the peripheral aryl rings of the terphenyl backbone, the diphenylphosphine groups are not constrained to any particular mutual orientation. The dihedral angles between the aromatic rings in the backbone are calculated to be 115.8 and $144.4^{\circ}$ giving rise to the different spatial arrangements of the phosphorus atoms.

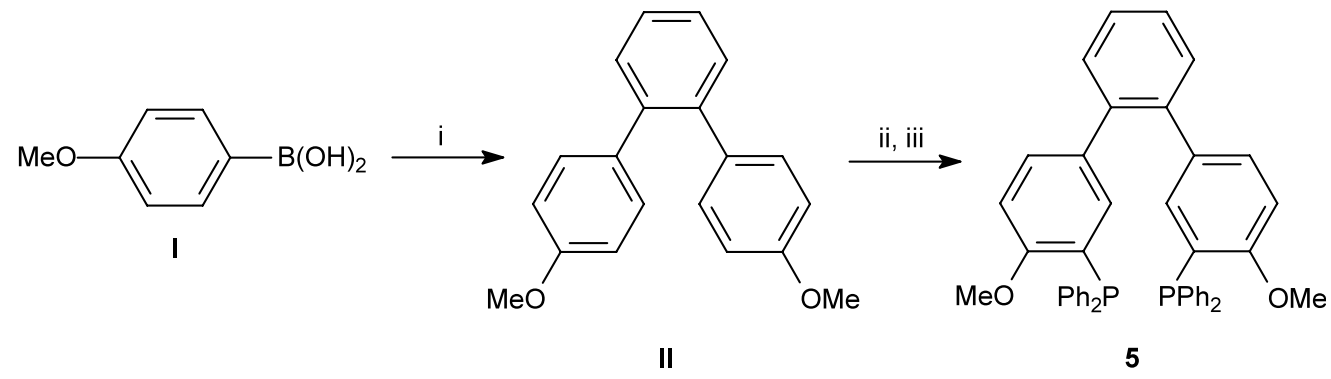

Scheme 2. Synthetic-route to ligand 5. Reagents and conditions: (i) 1,2-dibromobenzene, $\mathrm{Na}_{2} \mathrm{CO}_{3}, \mathrm{Pd}(\mathrm{PPh})_{4}, \mathrm{DME}, \mathrm{H}_{2} \mathrm{O}, \Delta, 16$ h, 85\%; (ii) $n$-BuLi, TMEDA, $-40^{\circ} \mathrm{C}, \mathrm{Et}_{2} \mathrm{O}, 16 \mathrm{~h}$; (iii) $\mathrm{ClPPh}_{2}$, hexanes, $0^{\circ} \mathrm{C}, 16 \mathrm{~h}, 60 \%$.

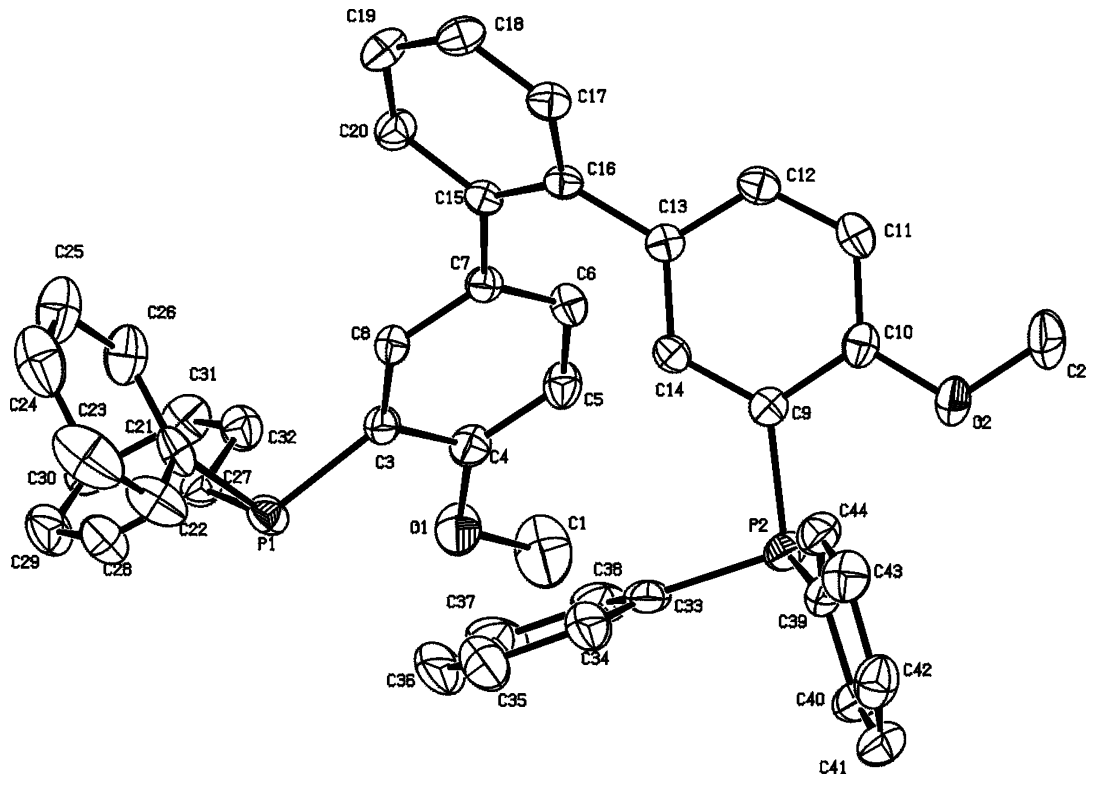

Figure 1. Ortep drawing of the crystal structure of ligand 5 (Terphos). Hydrogen atoms are omitted for clarity. Thermal ellipsoids are drawn at the $50 \%$ probability level. Selected bond lengths $(\AA): \mathrm{P}_{1}-\mathrm{C}_{3} 1.8322(19), \mathrm{P}_{2}-\mathrm{C}_{9} 1.8362(19), \mathrm{O}_{1}-\mathrm{C}_{1} 1.431(3), \mathrm{O}_{2}-\mathrm{C}_{2}$ 1.433(3). Selected bond angles $\left(^{\circ}\right)$ : $\mathrm{C}_{3}-\mathrm{P}_{1}-\mathrm{C}_{21}$ 101.85(9), $\mathrm{C}_{3}-\mathrm{P}_{1}-\mathrm{C}_{27}$ 105.36(8), $\mathrm{C}_{21}-\mathrm{P}_{1}-\mathrm{C}_{27}$ 101.13(9), $\mathrm{C}_{9}-\mathrm{P}_{2}-\mathrm{C}_{33} 101.81(9)$, $\mathrm{C}_{9}-\mathrm{P}_{2}-\mathrm{C}_{39} 104.56(9), \mathrm{C}_{33}-\mathrm{P}_{2}-\mathrm{C}_{39} 100.62(9), \mathrm{C}_{1}-\mathrm{O}_{1}-\mathrm{C}_{4} 117.83(18), \mathrm{C}_{2}-\mathrm{O}_{2}-\mathrm{C}_{10} 116.34(16), \mathrm{C}_{7}-\mathrm{C}_{15}-\mathrm{C}_{16} 124.69(16), \mathrm{C}_{13}-\mathrm{C}_{16}-\mathrm{C}_{15}$ $125.16(16)$. 
Our approach is not comparable to earlier work on the synthesis of ligands based on bisphenol A type backbones. To the best of our knowledge there are only two reports so far in the literature using bisphenol $\mathrm{A}$ as a building block for phosphorus ligands; however, they deal with the functionalization of the phenolic $\mathrm{OH}$ groups $^{10}$ and the formation of phosphite-bridged macrocycles. ${ }^{11}$

To illustrate the applicability of the new phosphorus ligands in homogeneous catalysis, we chose the rhodium catalyzed hydroformylation of 1-octene as an example (Scheme 3). The catalysis was carried out under typical hydroformylation conditions, 20 bar of syngas $\left(\mathrm{CO} / \mathrm{H}_{2} 1: 1\right)$ and a temperature of $80^{\circ} \mathrm{C}$.

There is a direct influence of the flexibility and steric crowding of the central-atom in the backbone skeleton on the activity of the corresponding catalyst. The least rigid ligand 1 (entry 1 , Table 1) gave a TOF of $735 \mathrm{~h}^{-1}$. The activity was improved to a TOF of $1029 \mathrm{~h}^{-1}$ when a cyclohexyl-moiety was present in the backbone of ligand 2 (entry 2) while with ligand 3 the activity increased further to a TOF of $1418 \mathrm{~h}^{-1}$ (entry 3). Selectivity for the terminal aldehyde is moderate with a linear to branched $(1 / \mathrm{b})$ ratio of about 3 . This is expected as these ligands are not optimized to obtain a high regioselectivity, as far as rigidity, bulkiness and bite-angle are concerned. For ligand 4 (entry 4) the activity was unexpected since it was thought to resemble ligand $\mathbf{1 .}$

Ligand 5 turned out to give the highest activity, with a turnover frequency up to nearly $3500 \mathrm{~h}^{-1}$ which leads to a conversion of nearly $22 \%$ after 15 min (entry 5). No side reactions such as hydrogenation and isomerization of the substrate occurred. Furthermore, the catalytic system based on Terphos (ligand 5) shows the typical behavior expected for diphosphine ligands concerning the influence of temperature, pressure and $\mathrm{CO} / \mathrm{H}_{2}$ ratio (entries 6-9).

In conclusion, we have described a two-step synthetic route to a new and modular class of phosphorus containing ligands, based on bisphenol A derived skeletons. As a first introduction four diphosphine ligands were prepared in good yields. Based on the same methodology, we used a new terphenyl backbone to obtain a fifth ligand, Terphos. For this ligand the X-ray structure is presented. In the rhodium-catalyzed hydroformylation of 1-octene high activities were obtained, especially for ligand $\mathbf{5}$. For this new class of ligands we are currently investigating the coordination with various transition metals and the activity in other catalytic reactions. The family will be extended by introduction of other phosphorus containing groups.

\section{Acknowledgements}

This work is financially supported by the National Research School Combination for Catalysis (NRSCC) and in part (A.M.M. and A.L.S.) by the Netherlands Foundation of Chemical Research (SON) with financial aid from the Netherlands Organisation for Scientific Research (CW-NWO). J.M.B. thanks the Erasmus program of the European Union for a travel grant. OMG is gratefully acknowledged for providing a stock of $\mathrm{Rh}(\mathrm{acac})(\mathrm{CO})_{2}$. We like to thank Dr. Ahlers and Dr. Paciello (BASF AG) and Dr. Rafael Sablong (TU/e) for valuable scientific discussions.

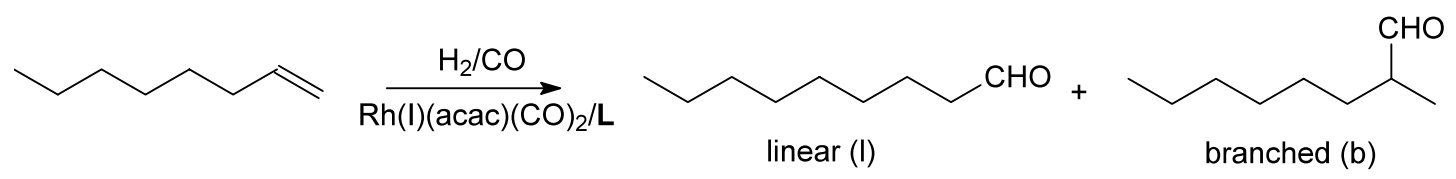

Scheme 3. Hydroformylation of 1-octene.

Table 1. Hydroformylation of 1-octene catalyzed by $\left[\mathrm{Rh}(\mathrm{acac})(\mathrm{CO})_{2}\right] / \mathbf{1}-\mathbf{5}^{\mathrm{a}}$

\begin{tabular}{|c|c|c|c|c|c|c|c|c|}
\hline Entry & Ligand & Time (min) & Temperature $\left({ }^{\circ} \mathrm{C}\right)$ & $p$ (bar) & Conversion $(\%)^{\mathrm{b}}$ & Sel. $_{\text {aldehyde }}(\%)^{\mathrm{b}}$ & $1 / \mathrm{b}$ ratio $^{\mathrm{b}}$ & TOF $\left(h^{-1}\right)^{\mathrm{c}}$ \\
\hline 1 & 1 & 60 & 80 & 20 & 18.8 & 97.9 & 2.8 & 735 \\
\hline 2 & 2 & 60 & 80 & 20 & 26.8 & 99.0 & 2.9 & 1029 \\
\hline 3 & 3 & 60 & 80 & 20 & 35.4 & 99.2 & 2.7 & 1418 \\
\hline 4 & 4 & 60 & 80 & 20 & 31.6 & 99.3 & 2.9 & 1250 \\
\hline 5 & 5 & 15 & 80 & 20 & 21.8 & 98.1 & 3.0 & 3485 \\
\hline 6 & 5 & 60 & 80 & 30 & 40.0 & 97.6 & 2.9 & 1615 \\
\hline 7 & 5 & 60 & 70 & 20 & 20.3 & 98.4 & 3.0 & 800 \\
\hline 8 & 5 & 60 & 60 & 20 & 8.3 & 98.3 & 3.0 & 325 \\
\hline 9 & 5 & 60 & 60 & $20^{\mathrm{d}}$ & 15.8 & 98.9 & 2.4 & 620 \\
\hline
\end{tabular}

a Reaction conditions: 1-octene $(31.0 \mathrm{mmol}),\left[\mathrm{Rh}(\mathrm{acac})(\mathrm{CO})_{2}\right](0.39 \mathrm{mM})$, decane $(12.5 \mathrm{mmol})$, toluene $(12.7 \mathrm{~mL}), 1-\mathrm{octene}: \mathrm{Rh}=4000: 1$, preformation time $1 \mathrm{~h}, \mathrm{~L}: \mathrm{Rh}=6: 1$.

${ }^{\mathrm{b}}$ Determined by GC.

${ }^{c}$ TOF in mol 1-octene $m o l \mathrm{Rh}^{-1} \mathrm{~h}^{-1}$ determined by GC.

${ }^{\mathrm{d}} p\left(\mathrm{H}_{2}\right): p(\mathrm{CO})=3: 1$. 


\section{References}

1. Frohning, C. D.; Kohlpainter, C. W.; Bohnen, H. W. In Applied Homogeneous Catalysis with Organometallic Compounds, 2nd ed.; Cornils, B.; Herrmann, W. A., Eds.; VCH: Weinheim, 2002; Vol. 1, p. 31.

2. (a) Devon, T. J.; Phillips, G. W.; Puckette, T. A.; Stavinoha J. L.; Vanderbilt, J. J. (to Eastman Kodak), US Patent 4694109, 1987 [Chem. Abs. 1988, 108, 7890]; (b) Devon, T. J.; Phillips, G. W.; Puckette, T. A.; Stavinoha, J. L.; Vanderbilt. J. J. (to Eastman Kodak), US Patent 5332846, 1994 [Chem. Abs. 1994, 121, 280879].

3. (a) Hillebrand, S.; Bruckmann, J.; Krüger, C.; Haenel, M. W. Tetrahedron Lett. 1995, 36, 75; (b) Kranenburg, M.; van der Burgt, Y. E. M.; Kamer, P. C. J.; van Leeuwen, P. W. N. M. Organometallics 1995, 14, 3081.

4. (a) Yamamoto, K.; Momose, S.; Funahashi, M.; Miyazawa, M. Synlett 1990, 711; (b) Casey, C. P.; Whiteker, G. T. J. Org. Chem. 1990, 55, 1394.

5. Ullmann's Encyclopedia of Industrial Chemistry, 6th electronic edition, Wiley-VCH: Weinheim, 2002.

6. Ahlers, W.; Paciello, R.; Vogt, D.; van der Vlugt, J. I. (to BASF AG), US Pat. Appl. 2002111517 [Chem. Abs. 2002, 137, 169060].

7. (a) Ahlers, W.; Wiebelhaus, D.; Paciello, R.; Bartsch, M.; Baumann, R.; Vogt, D.; Hewat, A. C. (to BASF AG) WO 222261, 2002 [Chem. Abs. 2002, 136, 249380]; (b) Goertz, W.; Kamer, P. C. J.; van Leeuwen, P. W. N. M.; Vogt, D. Chem. Eur. J. 2001, 7, 1614; (c) Goertz, W.; Keim, W.; Vogt, D.; Englert, U.; Boele, M. D. K.; van der Veen, L. A.; Kamer, P. C. J.; van Leeuwen, P. W. N. M. J. Chem. Soc., Dalton Trans. 1998, 2981.

8. Blake, A. J.; Cooke, P. A.; Doyle, K. J.; Gair, S.; Simpkins, N. S. Tetrahedron Lett. 1998, 39, 9093.

9. Crystal data for 5: $\left[\mathrm{C}_{44} \mathrm{H}_{36} \mathrm{O}_{2} \mathrm{P}_{2}\right], M_{\mathrm{w}}=658.67 \mathrm{~g} \mathrm{~mol}^{-1}$, triclinic space group $P \overline{1}$ (no. 2), $Z=2$ in cell with the following dimensions: $a=9.4589(1) \AA$ $\AA, c=18.4500(3) \AA, \alpha=80.1013(7)^{\circ}, \beta=76.3222(6)^{\circ}, \gamma=$ $78.9500(10)^{\circ}, V=1791.68(5) \AA^{3}, D_{\text {calcd }}=1.221 \mathrm{~g} \mathrm{~cm}^{-3}, 435$ parameters, 0 restraints, $R(F)=0.0467 \quad[I>2 \sigma(I)]$, $w R(F 2)=0.1193, S=1.03, \Delta_{\rho} \max / \Delta_{\rho} \min =0.39 /-0.34 \mathrm{e}$ $\AA^{-3}$. The data were collected at $150 \mathrm{~K}$ for a single crystal $\left(0.27 \times 0.15 \times 0.09 \mathrm{~mm}^{3}\right)$ on a Nonius Kappa CCD diffractometer with rotating anode $(\lambda(\mathrm{Mo} \mathrm{K} \alpha)=0.71073 \AA)$. Of $\mu=0.158 \mathrm{~mm}^{-1}, 28679$ measured reflections, and 8182 were unique reflections $\left(2 \theta_{\max }=27.5, R_{\mathrm{int}}=0.058\right)$. An absorption correction was considered unnecessary. The structure was solved by direct methods using SHELXS$97,{ }^{\mathrm{a} a}$ and refined on $F 2$ by least-squares procedures using SHELXL-97. ${ }^{9 \mathrm{~b}}$ All non-hydrogen atoms were refined with anisotropic displacement parameters. Hydrogen atoms were constrained to idealized geometries and allowed to ride on their carrier atoms with an isotropic displacement parameter related to the equivalent displacement parameter of their carrier atoms. Structure validation and molecular graphics preparation were performed with the PLATON package. ${ }^{9 c}$ CCDC 198081 contains the supplementary crystallographic data for this paper. These data can be obtained free of charge via http://www.ccdc.cam.ac.uk/conts/retrieving.html (or from the CCDC, 12 Union Road, Cambridge CB2 1EZ, UK; fax: +44 1223 336033; e-mail: deposit@ccdc.cam.ac.uk). (a) Sheldrick, G. M. SHELXS-97. University of Göttingen, Germany, 1997.

(b) Sheldrick, G. M. SHELXL-97. University of Göttingen, Germany, 1997.

(c) Spek, A. L. PLATON, A Multipurpose Crystallographic Tool, Utrecht University, The Netherlands, 2002.

10. Arena, C. G.; Drommi, D.; Faraone, F.; Graiff, C.; Tiripicchio, A. Eur. J. Inorg. Chem. 2001, 247.

11. Bauer, I.; Habicher, W. D. Tetrahedron Lett. 2002, 43, 5245. 